\title{
Theoretical typology of deceptive content (Conspiracy Theories)
}

\section{AUTHOR}

Jing Zeng

\section{KEYWORDS}

misinformation, disinformation, rumour, gossip, urban legend, propaganda, and conspiracy theories

\section{BRIEF DESCRIPTION}

The conceptual fuzziness of terms like misinformation, disinformation, rumour, gossip, conspiracy theories has been discussed by various scholars (e.g. DiFonzo \& Bordia, 2007; Rojecki \& Meraz, 2016). In both academic research and media reports, it is common to see these terms being used interchangeably. To develop better understanding of how and why different forms of misinformation operate, it is important to clarify the conceptual boundaries between these terms in a meaningful way.

\section{FIELD OF APPLICATION/THEORETICAL FOUNDATION} In their social psychology research, DiFonzo and Bordia (2007) propose an effective way to differentiate rumour from other terms, which emphasises the content, function, and context of each concept. This three-dimensional frame- work can be applied to systematically differentiate concepts related to misinformation.

In the field of media and communication studies, as research on digital misinformation continues to grow, it is crucial for researchers to understand the contexts of each concept and choose the appropriate term in accordance with their research agenda. It is worth noting that there are also overlapping dimensions between these concepts. For instance, rumour can contain misinformation, and conspiracy theories can be used for propaganda.

\section{EXAMPLE STUDY}

Zeng (2018)

\section{INFORMATION ON ZENG, 2018}

Author: Jing Zeng

Interest of the study: In her study on online rumours during times of crises, Zeng (2018) applies DiFonzo and Bordia's (2007) framework to differentiate seven seemingly similar concepts: misinformation, disinformation, rumour, gossip, urban legend, propaganda, and conspiracy theories.

\begin{tabular}{llll}
\hline Table 1. Summary of main features of seven concepts related to misinformation. & Context & Function \\
\hline Content & Inaccurate information & $\begin{array}{l}\text { Any circumstances of } \\
\text { information circula- } \\
\text { tion. }\end{array}$ & $\begin{array}{l}\text { Does not have to have } \\
\text { any specific function }\end{array}$ \\
\hline Gossip & $\begin{array}{l}\text { Talk about individuals } \\
\text { or private behaviour }\end{array}$ & $\begin{array}{l}\text { Shared between indivi- } \\
\text { duals or in casual social } \\
\text { events. }\end{array}$ & $\begin{array}{l}\text { Maintaining network, } \\
\text { interpersonal relations }\end{array}$ \\
\hline
\end{tabular}


Urban legend

Meaning-making, value-endorsing stories related to contemporary life

Disinformation Deliberately deceptive information
Casual setting for story- Promote cultural and telling. moral values

\section{Disseminated by insti- Undermine public tutions. \\ support}

\section{Propaganda \\ Messages instrumental- ly disseminated to pro- mote a political cause \\ Following a top-down pattern, disseminated by official sources. \\ Promote political and ideological values}

\begin{tabular}{llll}
\hline Rumour & $\begin{array}{l}\text { Unofficial information } \\
\text { unverified by authori- } \\
\text { ties }\end{array}$ & $\begin{array}{l}\text { Circulated in circums- } \\
\text { tances of ambiguity, } \\
\text { danger or threat. }\end{array}$ & $\begin{array}{l}\text { Make sense of an un- } \\
\text { certain circumstance }\end{array}$ \\
$\begin{array}{l}\text { Conspiracy } \\
\text { theory }\end{array}$ & $\begin{array}{l}\text { Proposed explanations } \\
\text { of an event or a practice } \\
\text { that refer to the machi- } \\
\text { nations of influential } \\
\text { people, institutions, or } \\
\text { a secret society }\end{array}$ & $\begin{array}{l}\text { Emerged in responses } \\
\text { to uncertainty and } \\
\text { berceived threats posed }\end{array}$ & $\begin{array}{l}\text { Serves as a threat } \\
\text { secret actors, and cons- } \\
\text { tructed as 'alternative' } \\
\text { and often also as an } \\
\text { anti-establishment/anti- } \\
\text { science, political and } \\
\text { ideological stance }\end{array}$ \\
\hline
\end{tabular}

Misinformation is the most generic one among these terms, in the sense that it does not emphasise the social and political dimension of information. The concept of misinformation is mostly discussed in tandem with information, particularly by Information Science scholars. As a form of information, the defining feature of misinformation is its inaccuracy. Such inaccuracy is not necessarily caused by false information, but can also be caused by irrelevant and incomplete information.

Gossip is also a form of unverified information; however, the content is more private, and is mostly circulated in an interpersonal context (DiFonzo \& Bordia, 2007; Rojecki \& Meraz, 2016). In terms of function, instead of sense making, gossip is propagated for social purposes. As summarised by Foster (2004), gossip functions to achieve the formation, adaptation, and maintenance of social networks. This is to say, individu- als share gossip in the context of managing their relationship with members within their social group. For instance, early literature on gossip associated the practice of gossiping with female social networking. As Rysman (1977) pointed out, one key reason behind the patriarchal criticism on female gossiping is gossip's ability 'to develop social ties outside the institution of male dominance' (p. 176). This personal and interpersonal focus on the concept of gossip is its most distinctive feature.

Disinformation and propaganda are two very closely related concepts, because they are both disseminated for political purposes (Lewandowsky, Stritzke, \& Freund, 2013). In terms of content, disinformation is deliberately deceptive information that is used to undermine public support of a regime, whereas propaganda is information used to mobilise public support for a political 
cause or a regime (Rojecki \& Meraz, 2016). The word disinformation originated from 'dezinformacija', a Russian term coined in the former Soviet Union (Karlova \& Fisher, 2013). Given the particular cultural and political context in the region at that time, this term was originally closely associated with intelligence operations and political tactics. However, the definition of disinformation has, over time, expanded to include the propagation of misinformation that is non-politically motivated.

Urban legends are contemporary tales that are shared to promote moral and cultural values (DiFonzo \& Bordia, 2007). Construed in this way, urban legends are similar to propaganda in the sense that they encode and transmit values, but they are used mythologically rather than strategically. Furthermore, where propaganda emphasises political and ideological values, urban legends focus on cultural and moral values. One key criterion for an urban legend is that it must be grounded in the day-to-day affairs of contemporary life, hence the 'urban' in urban legend (Bennett \& Smith, 2013). A classic example of an urban legend is the claim that a tooth left in a glass of Coca Cola can dissolve overnight. This story promotes health messages to avoid excessive consumption of soda drinks. Another case is the tale of a drugged traveller awakening in an ice-filled bathtub, only to discover one of his kidneys has been removed by organ thieves. This tale echoes a classic form of legend that teaches the moral lesson to avoid dangerous situations.

Rumour, in terms of content, is unofficial information - that is, information whose authenticity is not verified by an appeal to authority. By this definition, the defining characteristic of rumour content is not its falsity, but its 'unofficial' status and therefore its relationship to social institutions (Fine, 2007). Second, rumour arises in contexts that are ambiguous, threatening or potentially threatening (DiFonzo \& Bordia, 2007, p. 20). In such uncertain contexts, rumour functions to make sense of the unknown situation. This may explain why rumour goes hand in hand with crisis events, during which there is often a paucity of information and a state of anxiety among the populace.

Conspiracy theories' content is proposed explanations of an event or a practice that refer to the machinations of powerful people, institutions, or a secret society (e.g. Coady, 2003; Goertzel,
1994; Keeley, 1999). One distinctive feature of conspiracy theories is its reference to a coordinated group of deliberate actors. For instance, in anti-vaccination conspiracy theories, "big pharma' companies are accused of conspiring with politicians; likewise, flat earthers implicate NASA in the plot to keep the truth about the "true nature" of the Earth from the public. Similar to rumour mongering, the context in which conspiracy theories emerge is often one of uncertainty and perceived risks, and conspiracy theorising represents a form of 'alternative' collective sensemaking to challenge established narratives provided by the mainstream media and institutions. Therefore, conspiracy theorising is not merely sensemaking, but also has anti-establishment and anti-science undercurrents. Therefore, in terms of function, conspiracy theories serve as (1) a threat management response to 'secret coalitions' that are perceived to pose direct threats to the collective well-being, health, and safety of the society (van Prooijen et al., 2018); and (2) a political and ideological stance (Hofstadter, 2012).

\section{REFERENCES}

Bennett, G., \& Smith, P. (2013). Contemporary legend: A reader. London: Routledge.

Coady, D. (2003). Conspiracy theories and official stories. International Journal of Applied Philosophy, 17(2), 197-209.

DiFonzo, N., \& Bordia, P. (2007). Rumor, gossip and urban legends. Diogenes, 54(1), 19-35.

Fine, G. A. (2007). Rumor, trust and civil society: Collective memory and cultures of judgment. Diogenes, 54(1), 5-18.

Foster, E. K. (2004). Research on gossip: Taxonomy, methods, and future directions. Review of General Psychology, 8(2), 78-99.

Goertzel, T. (1994). Belief in conspiracy theories. Political Psychology, 15, 731-742.

Hofstadter, R. (2012). The paranoid style in American politics. New York: Vintage.

Karlova, N. A., \& Fisher, K. E. (2013). A social diffusion model of misinformation and disinformation for understanding human information behaviour. Information Research, 18(1), paper 573.

Keeley, B. L. (1999). Of conspiracy theories. The Journal of Philosophy, 96(3), 109-126. Lewandowsky, S., Stritzke, W. G. K., Freund, A. M, Oberauer, K., and Krueger, J. I. 
(2013). Misinformation, disinformation, and violent conflict: From Iraq and the 'War on Terror' to future threats to peace. American Psychologist, 68(7), 487-501.

Losee, R. M. (1997). A discipline independent definition of information. Journal of the American Society for Information Science, 48(3), 254-269

Rojecki, A., \& Meraz, S. (2016). Rumors and factitious informational blends: The role of the web in speculative politics. New Media \& Society, 18(1), 25-43.

Rysman, A. (1977). How the 'gossip' became a woman. Journal of Communication, 27(1), 176-180.

van Prooijen, J. W., \& Van Vugt, M. (2018). Conspiracy theories: Evolved functions and psychological mechanisms. Perspectives on psychological science, 13(6), 770-788.

Zeng, J. (2018). Contesting rumours on social media during acute events: The 2014 Sydney siege and 2015 Tianjin blasts (Doctoral dissertation, Queensland University of Technology). Available at https://eprints.qut.edu.au/115786/. 